\title{
Levantamento florístico e síndromes de dispersão em remanescentes de Floresta Ombrófila Mista na região centro-sul do estado do Paraná
}

\author{
Dieter Liebsch ${ }^{1,5}$, Sandra Bos Mikich ${ }^{2}$, Rafael Fernando da Silva Possette ${ }^{3}$ e Osmar dos Santos Ribas ${ }^{4}$
}

Recebido: 28.02.2008; aceito: 20.03.2009

\begin{abstract}
Floristic survey and dispersal syndromes in Araucaria Forest remnants of Parana state, Brazil). This study presents a list of plants found in three areas of Araucaria Forest along with their dispersal syndromes. We sampled monthly (August 2003 to December 2005) five transects with $5 \mathrm{~km}$ each, collecting samples of flowering and fruiting plants. We identified 210 species, including 83 trees, 58 shrubs, 36 herbs, 23 vines, eight epiphytes and two parasites. Most species were zoochorous $(68.6 \%)$, followed by anemochorous $(21.9 \%)$ and autochorous $(6.7 \%)$ ones. Comparisons with other florist surveys previously conducted in this forest type suggested that our study areas are poor, both when all species are taken into account or when just trees are. The results are discussed based on the history of degradation of the study region and on the abundance of bamboos in the understory.
\end{abstract}

Key words: Araucaria Forest, conservation, floristic diversity, phytogeography

RESUMO - (Levantamento florístico e síndromes de dispersão em remanescentes de Floresta Ombrófila Mista na região centro-sul do estado do Paraná). O presente estudo apresenta a listagem das espécies vegetais de três áreas de Floresta com Araucária e as suas respectivas síndromes de dispersão. Foram percorridos mensalmente (agosto/2003 a dezembro/2005) cinco transectos com $5 \mathrm{~km}$ cada, ao longo dos quais foi coletado material fértil, resultando na identificação de 210 espécies: 83 árvores, 58 arbustos, 36 ervas, 23 trepadeiras, oito epífitas e duas parasitas. A maioria $(68,6 \%)$ das espécies possui dispersão zoocórica, seguidas pelas espécies anemocóricas $(21,9 \%)$ e autocóricas $(6,7 \%)$. Comparações florísticas com áreas recobertas pela mesma formação florestal sugerem que os remanescentes estudados apresentam baixa riqueza específica, tanto quando a comparação é realizada considerando todas as formas de vida como quando apenas as espécies arbóreas são consideradas. Os resultados são discutidos à luz do histórico de exploração da região de estudo e da abundância de taquaras no sub-bosque.

Palavras-chave: conservação, diversidade florística, fitogeografia, Floresta com Araucaria

\section{Introdução}

A Floresta Ombrófila Mista (FOM) distribui-se, principalmente, nos estados do sul do Brasil, sendo inconfundível fisionomicamente devido à presença da araucária (Araucaria angustifolia (Bertol.) O. Kuntze), espécie típica e caracterizadora desse bioma (IBGE 1992), que também é conhecido como Floresta com Araucária. No entanto, a FOM pode ser definida como uma mistura de floras de diferentes origens, definindo padrões fitofisionômicos típicos, em zona climática caracteristicamente pluvial, sem influência direta do oceano, e com chuvas bem distribuídas ao longo do ano (IBGE 1992). Segundo Roderjan et al. (2002), a composição florística da FOM é fortemente influenciada pelas baixas temperaturas e pela ocorrência regular de geadas no inverno.

Em sua distribuição original, a FOM recobria cerca de $200.000 \mathrm{~km}^{2}$, ocupando $40 \%$ da superfície do estado do Paraná, $31 \%$ de Santa Catarina e 25\% do Rio Grande do Sul, além de estar representada por manchas esparsas no sul de São Paulo, onde ocupava 3\% do território, e sul de Minas Gerais e Rio de Janeiro (1\%) (Klein 1960). No entanto, ao longo do processo histórico de ocupação do sul do Brasil, iniciado a partir de 1895 , assistiu-se a rápida eliminação de sua cobertura florestal, tanto para fins de extração de madeira como para dar espaço

1. Remasa Reflorestadora Ltda., Rodovia PR 170, Km 529, Caixa Postal 09, 84640-000 Bituruna, PR, Brasil

2. Embrapa Florestas, Laboratório de Ecologia, Caixa Postal 319, 83411-000 Colombo, PR, Brasil

3. Universidade Federal do Paraná, Setor de Ciências Biológicas, Pós-Graduação em Botânica, Caixa Postal 19.031, 81531 Curitiba, PR, Brasil

4. Museu Botânico Municipal de Curitiba, Caixa Postal 1142, 80210-390 Curitiba, PR, Brasil

5. Autor para correspondência: dieterliebsch@yahoo.com.br 
a atividades agropecuárias (Maack 1981). Assim, atualmente estima-se que no estado do Paraná restem apenas $0,8 \%$ da FOM em bom estado de conservação, sendo a situação desse importante bioma crítica, já que seus remanescentes são pequenos ou médios e estão dispersos na paisagem (Castella \& Britez 2004). Apesar disso, a pressão sobre ele continua por meio da extração ilegal de essências florestais e da sua substituição por outros usos da terra, como a pecuária e as florestas plantadas (Castella \& Britez 2004). Portanto, programas de conservação e restauração da FOM se fazem necessários. No entanto, para que sua implementação seja viável, a diversidade biológica dos remanescentes da FOM precisa ser inventariada com urgência e em detalhe. Nesse sentido é importante destacar que a maioria dos estudos florísticos conduzidos nesse bioma contemplou apenas as árvores (Longhi 1980, Carvalho 1980, Oliveira \& Rotta 1982, Galvão et al. 1989, Roseira 1990, Negrelle \& Silva 1992, Koehler et al. 1998, Sanquetta et al. 2001), sendo raros aqueles que abrangeram todas as formas de vida (Britez et al. 1995, Kozera et al. 2006).

Com esta perspectiva, o presente trabalho teve como objetivo principal apresentar uma listagem das espécies vegetais presentes em três áreas de Floresta Ombrófila Mista, localizadas nos municípios de Bituruna, General Carneiro e Palmas, no centrosul do estado do Paraná, além de investigar as suas síndromes de dispersão, para subsidiar programas de conservação e recuperação dessa formação florestal, que foi apontada pelo Ministério do Meio Ambiente (MMA 2000) como de extrema importância biológica para a conservação da biodiversidade.

\section{Material e métodos}

Áreas de estudos - O trabalho foi desenvolvido em duas áreas pertencentes à Remasa Reflorestadora Ltda. e no extinto Parque Estadual das Araucárias, pertencente às Indústrias Pedro N. Pizzatto Ltda, localizadas nos municípios de Bituruna, General Carneiro e Palmas $\left(26^{\circ} 14-26^{\circ} 22^{\prime} \mathrm{S}\right.$ e $\left.51^{\circ} 34^{\prime}-51^{\circ} 39^{\prime} \mathrm{W}\right)$ (figura 1). As três áreas, juntas, somam cerca de 3.000 ha de remanescentes de FOM com diferentes graus de perturbação e 3.500 ha de plantios de Pinus spp. O clima, segundo Köppen, é o subtropical úmido mesotérmico $(\mathrm{Cfb})$ com média do mês mais quente superior a $22{ }^{\circ} \mathrm{C}$ e do mês mais frio inferior a $18{ }^{\circ} \mathrm{C}$, sem estação seca, verão brando e geadas severas e freqüientes (Maack 1981). As altitudes variam entre 900 a $1.100 \mathrm{~m}$ e a topografia é fortemente ondulada a montanhosa. Os solos nesta região apresentam textura argilosa e forte declividade (Maack 1981).

Essas áreas sofreram as primeiras alterações em sua composição em meados da década de 50 do século passado, com a retirada de espécies madeiráveis, notadamente araucária (A. angustifolia) e imbuia (Ocotea porosa). Logo após, grandes extensões florestais foram substituídas por plantios comerciais de espécies exóticas, principalmente do gênero Pinus. Assim, atualmente, tem-se um mosaico complexo de plantios florestais e florestas nativas em diversos estádios sucessionais e em diferentes graus de conservação, muitas vezes interligadas por corredores, representados principalmente pelas florestas ciliares. Com isso, a definição dos limites e dos tamanhos dos hábitats florestais é dificultada e os transectos (vide abaixo) refletem essa complexidade.

Metodologia - Para o levantamento florístico foram utilizados cinco transectos com $5 \mathrm{~km}$ de extensão cada. Os transectos foram percorridos mensalmente, de agosto de 2003 a dezembro de 2005, quando foram coletadas amostras de material fértil (flores e frutos) de várias formas de vida, incluindo árvores, arbustos, ervas, trepadeiras e epífitas, segundo classificação de Vidal \& Vidal (1984). Foram coletadas todas as espécies que estavam férteis ao alcance do campo de visão. No caso das pteridófitas foram coletadas apenas as espécies arborescentes. Todo material coletado foi herborizado e tombado no Herbário Fernando Cardoso da Silva (HFC) da Embrapa Florestas, Colombo - PR.

Na Fazenda Lageado Grande (Município de Bituruna) foram instalados três transectos, chamados de: Araucária, Reserva e Palmital. O transecto denominado Santa Cruz foi estabelecido na fazenda de mesmo nome (Município de Palmas) e o transecto Parque na área do extinto Parque Estadual das Araucárias (Município de General Carneiro). Os transectos apresentavam as seguintes características: Transecto Araucária - compreendia três fitofisionomias: um plantio de Pinus taeda com 30 anos, onde praticamente não havia ocorrência de espécies de sub-bosque; um plantio de araucária (Araucaria angustifolia), com 40 anos, cujo dossel era contínuo, formado pela própria araucária e por canela-guaicá (Ocotea puberula) e o sub-bosque, rico em espécies, era composto por indivíduos arbustivos, porém não atingia $7 \mathrm{~m}$ de altura; uma floresta secundária em estádio inicial de desenvolvimento que apresentava pouca regeneração natural em conseqüência da abundância da taquara (Merostachys sp.). 


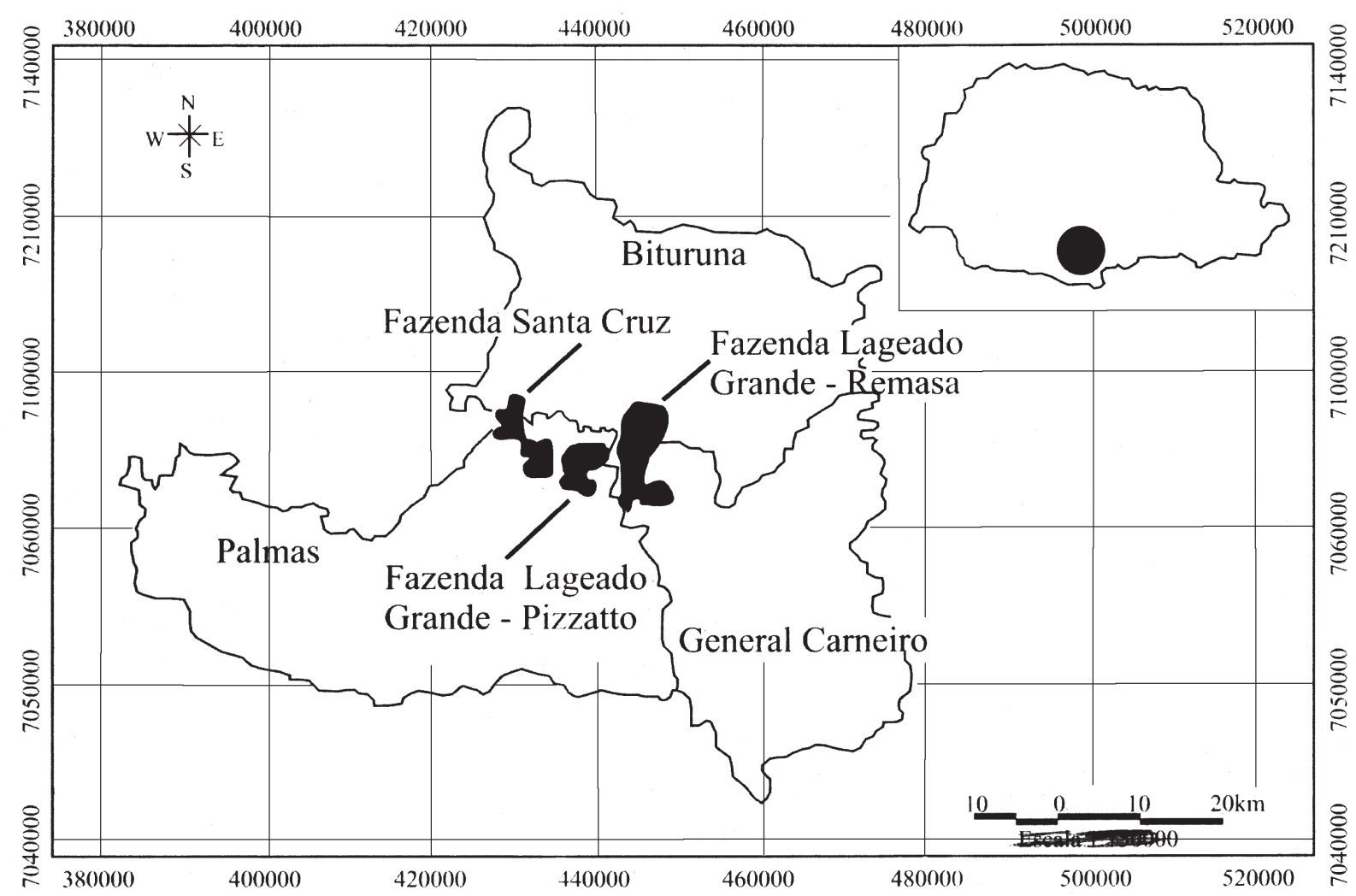

Figura 1. Localização das áreas de estudo na região centro-sul do estado do Paraná.

Figure 1. Location of study areas in the mid-southern region of Parana state, Brazil.

Transecto Reserva - floresta secundária em estádio médio de regeneração, com indivíduos arbóreos que atingiam $20 \mathrm{~m}$ de altura; ausência de araucária; no sub-bosque predominava a taquara, formando densos agrupamentos, muitas vezes intransponíveis, que acabavam suprimindo a regeneração natural.

Transecto Palmital - floresta em estádio médio de regeneração, apresentava alguns indivíduos de araucária com 15 m e densidade elevada de indivíduos jovens de imbuia (Ocotea porosa); sub-bosque composto por muita taquara. Outra porção do transecto era ocupada por plantios de P. taeda com 35 anos e cerca de $30 \mathrm{~m}$ de altura.

Transecto Santa Cruz - compreendia duas fitofisionomias, um plantio de Pinus elliottii com 23 anos, onde o estrato inferior era praticamente inexistente, e uma floresta em estádio inicial ocupada por taquaras. Porém, onde não havia ocorrência de taquaras, era observada uma maior riqueza de espécies, principalmente de indivíduos jovens, incluindo a araucária.

Transecto Parque - floresta em estádio inicial de desenvolvimento, porém com alta densidade de araucárias com até $30 \mathrm{~m}$ de altura, intercaladas com imbuias de grande porte; sub-bosque composto por alta densidade de taquaras e xaxim.

Análises - As espécies inventariadas nas áreas de estudo foram agrupadas em três categorias de síndromes de dispersão, de acordo com Pijl (1972): zoocóricas, anemocóricas ou autocóricas. Seis espécies (três espécies de pteridófitas, duas gimnospermas e Langsdorffia hypogaea) não tiveram a síndrome de dispersão definida.

As comparações florísticas entre os cincos transectos e entre as diferentes áreas foi efetuada utilizando o Índice de Similaridade de Jaccard, associado a uma análise de agrupamentos (UPGMA), para isso foi utilizado o programa BioDiversity Professional. Para isso, foram utilizadas todas as formas de vida, mas foram excluídas as espécies não determinadas em nível específico.

O enquadramento taxonômico das espécies de Angiospermas seguiu o Angiosperm Phylogeny Group (APG II 2003) e a consulta da grafia dos nomes científicos para cada espécie foi realizada por meio de consultas on line ao site do Missouri Botanical Garden (http://www.tropicos.org). 


\section{Resultados e Discussão}

Levantamento florístico - Após dois anos de coletas, foram registradas 210 espécies nos cinco transectos (tabela 1), sendo 83 arbóreas (39,5\%), 58 arbustivas $(27,6 \%), 36$ herbáceas $(17,1 \%), 23$ trepadeiras $(11 \%)$, oito epífitas $(3,8 \%)$ e duas parasitas $(1 \%)$. A riqueza total, embora superior a da maioria dos inventários previamente realizados em remanescentes da Floresta Ombrófila Mista (tabela 2) e citados por Isernhagen (2001), deve ser vista com cautela, pois a maioria desses trabalhos contemplou apenas espécies arbóreas, alguns incluíram também espécies arbustivas e apenas dois trataram de arbustos, árvores, trepadeiras e epífitas, como o presente estudo. Destes, o primeiro, conduzido em São Mateus do Sul (PR) por Britez et al. (1995), registrou 307 espécies e o segundo, realizado em Curitiba (PR) por Kozera et al. (2006), encontrou 390 espécies, valores, portanto, bastante superiores aos registrados no presente estudo (tabela 3 ).

A similaridade florística entre o presente levantamento e aquele conduzido por Britez et al. (1995) foi de $\mathrm{Sj}=38$. Apesar de ser considerado como similar ( $>25 \%$ ), é baixo se considerarmos que a distância entre as nossas áreas de estudo e São Mateus do Sul é de cerca de $120 \mathrm{~km}$ e estão praticamente todas na mesma faixa latitudinal. Um dos fatores que pode explicar a diferença entre as áreas é a altitude, que influencia significativamente a composição florística (Silva \& Shepherd 1986). Enquanto as altitudes das nossas áreas de estudo variam de 900 a 1000 m, a área estudada por Britez et al. (1995) estava a 760 m. Além disso, segundo Castella \& Britez (2004), a região centro-sul do estado do Paraná, onde estão localizados os remanescentes estudados no presente trabalho, apresenta grandes extensões cobertas com vegetação nativa, porém, a maioria é composta por vegetação em estádio inicial e médio de sucessão, onde o pastoreio e o manejo de erva-mate são atividades muito freqüentes, tendo efeitos negativos sobre a riqueza de espécies. Apesar da área estudada por Britez et al. (1995) estar localizada em uma região em situação ainda mais crítica (Castella \& Britez 2004), as coletas foram realizadas nas formações de várzea do rio Iguaçu (floresta ciliar e campos de inundação), onde o número de espécies restritas a esses ambientes é elevado. Além disso, no caso das pteridófitas foram consideradas todas as espécies, totalizando 16 espécies, ao contrário do presente estudo, no qual apenas as formas arborescentes $(n=3)$ foram incluídas na amostragem. Assim, considerando o esforço de coleta (2 anos) empreendido por Britez et al. (1995) e o resultado, em termos de diversidade florística, obtido por esses autores, pode-se sugerir que as áreas estudadas encontram-se empobrecidas.

O segundo trabalho a considerar todas as formas de vida foi aquele desenvolvido por Kozera et al. (2006) em um parque urbano de Curitiba e o que registrou a maior riqueza ( $n=390$ espécies) entre todos os levantamentos analisados. Trata-se de uma área com porções bem conservadas, que abrigam elevada riqueza de árvores das famílias Myrtaceae (23) e Lauraceae (11), além de porções com uso intensivo com um grande número de espécies arbustivas das famílias Solanaceae (16) e Asteraceae (14). A similaridade florística encontrada entre este trabalho (Kozera et al. 2006) e o nosso foi de $\mathrm{Sj}=4,2$. Esse baixo valor observado pode ser reflexo da elevada distância geográfica entre as duas áreas $(270 \mathrm{~km})$, apesar de ambos estarem situados na mesma zona altitudinal ( $900 \mathrm{~m}$ ) ou do esforço de coletas (dois anos com coletas semanais) na área em Curitiba, que foi significativamente maior. Além disso, a inclusão de espécies arbustivas da família Asteraceae e Poaceae (45 espécies, somadas as duas famílias), pteridófitas não-arborescentes (46 espécies) e de espécies herbáceas (129 espécies) por Kozera et al. (2006), foi outro fator que contribuiu para aumentar a dissimilaridade entre as duas áreas.

Dentre os trabalhos que contemplaram apenas espécies arbóreas, merece destaque o de Carvalho (1980), que além de não se restringir às parcelas, teve longa duração (sete anos) e foi conduzido no município de Irati-PR, que dista $130 \mathrm{~km}$ das nossas áreas de estudo. Ali, em uma localidade descrita como em bom estado de conservação por Castella \& Britez (2004), o autor registrou 97 espécies de árvores, sugerindo que nas nossas áreas de estudo tenha ocorrido uma super exploração de algumas espécies com elevado valor comercial (p.ex., Lauraceae e Fabaceae), somada à dificuldade no estabelecimento de plântulas dessas espécies, possivelmente em função da alta densidade de taquaras no sub-bosque (Smith et al. 1981, Oliveira Filho et al. 1994), abundante em nossas áreas de estudo (Liebsch \& Reginato, dados não publicados).

Outro fator a considerar quando da comparação entre os inventários florísticos (tabela 2) obviamente é o tamanho da área amostral e o esforço de coleta. Nos trabalhos que efetuaram expedições para coletas, sem definição de área fixa, o número de espécies inventariadas foi superior a 100 (Carvalho 1980, 


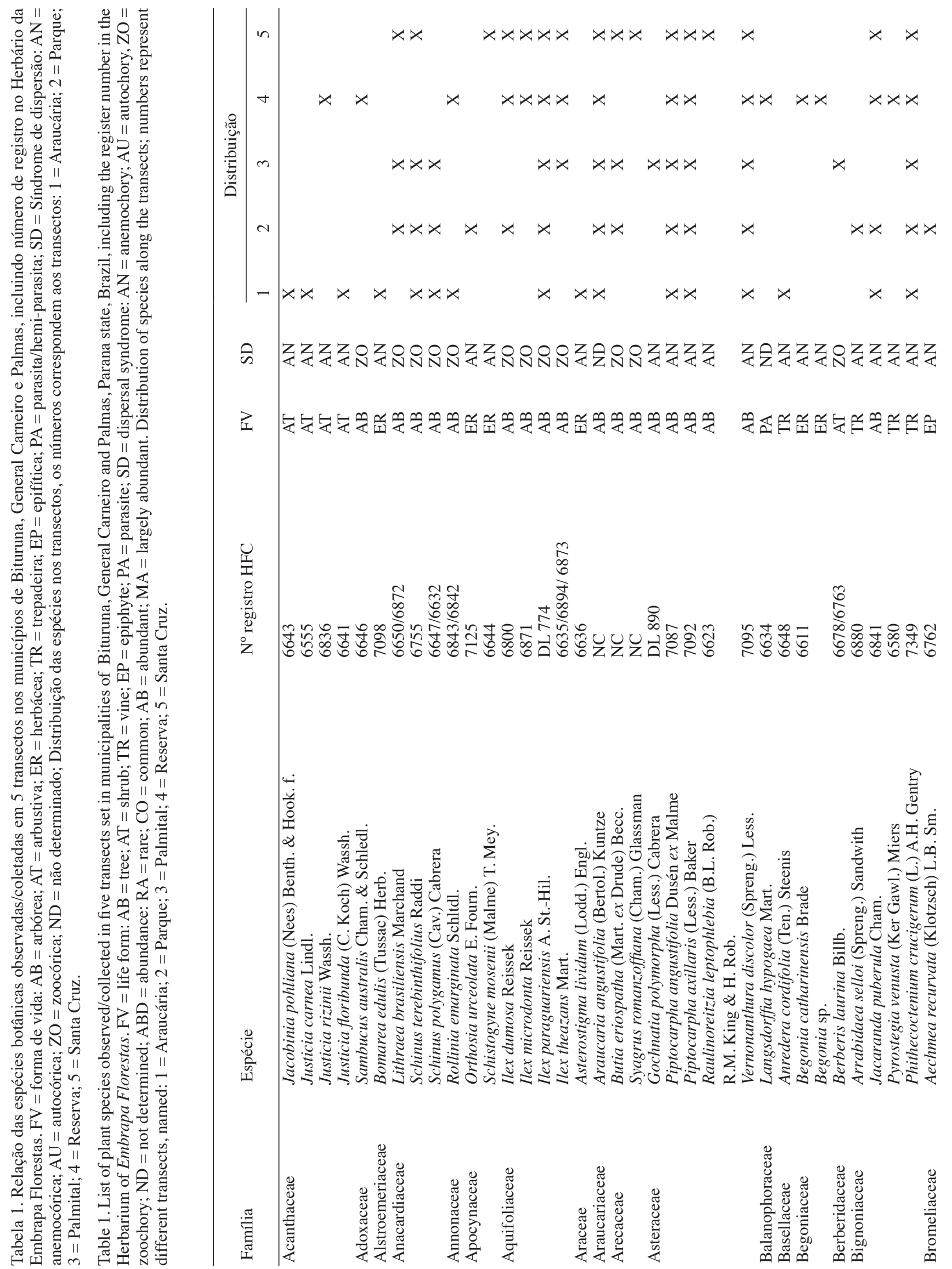




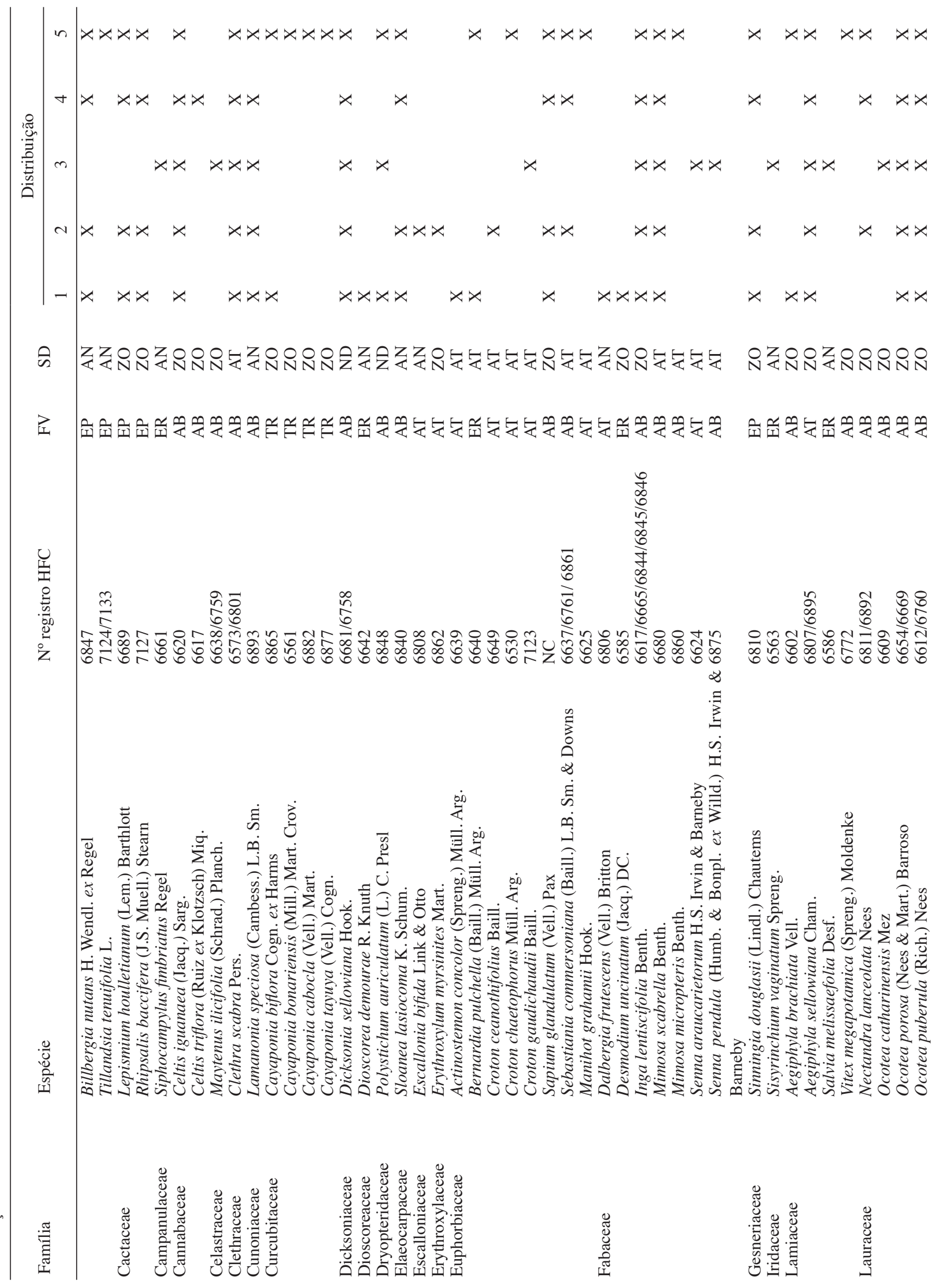




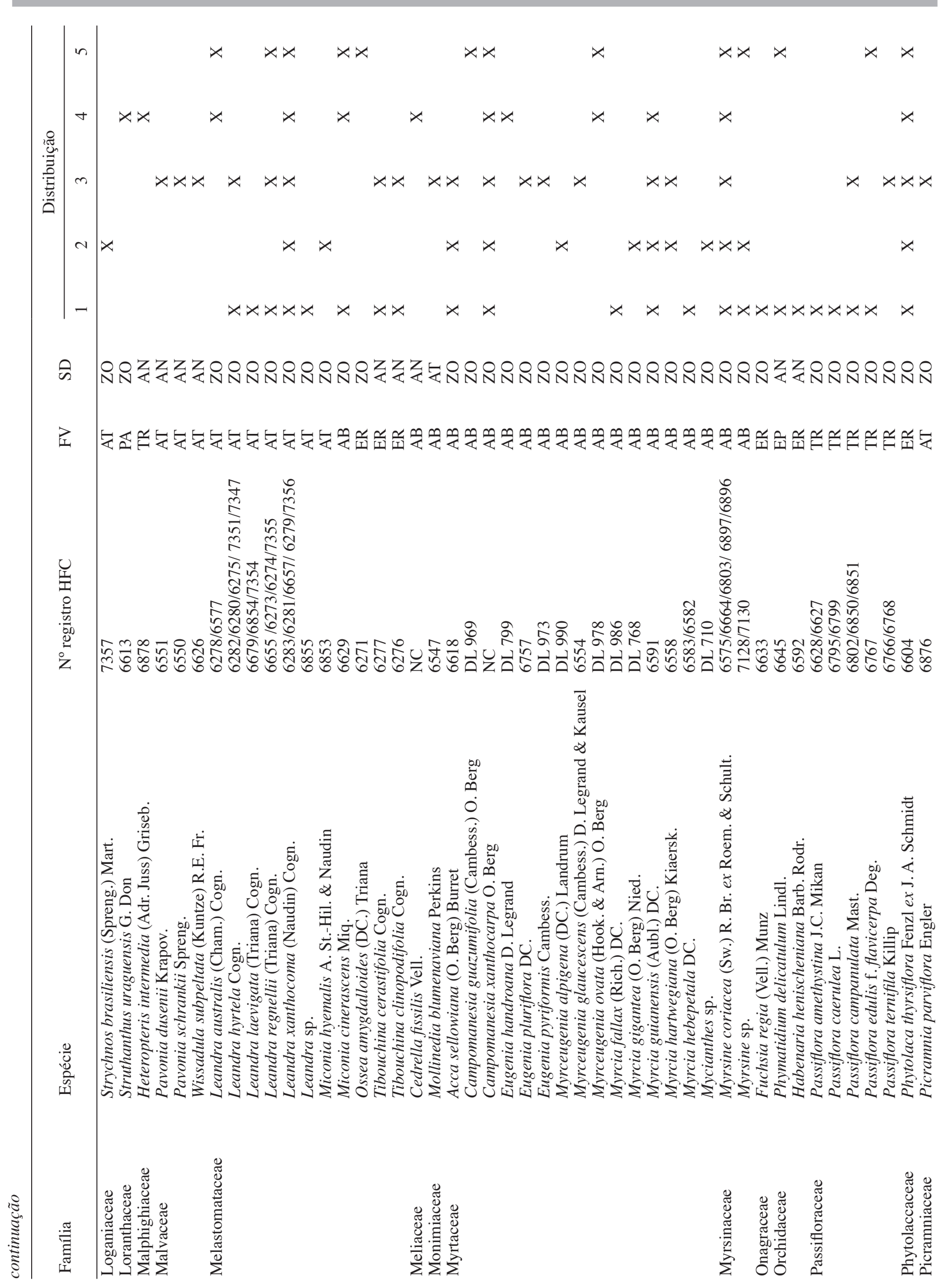




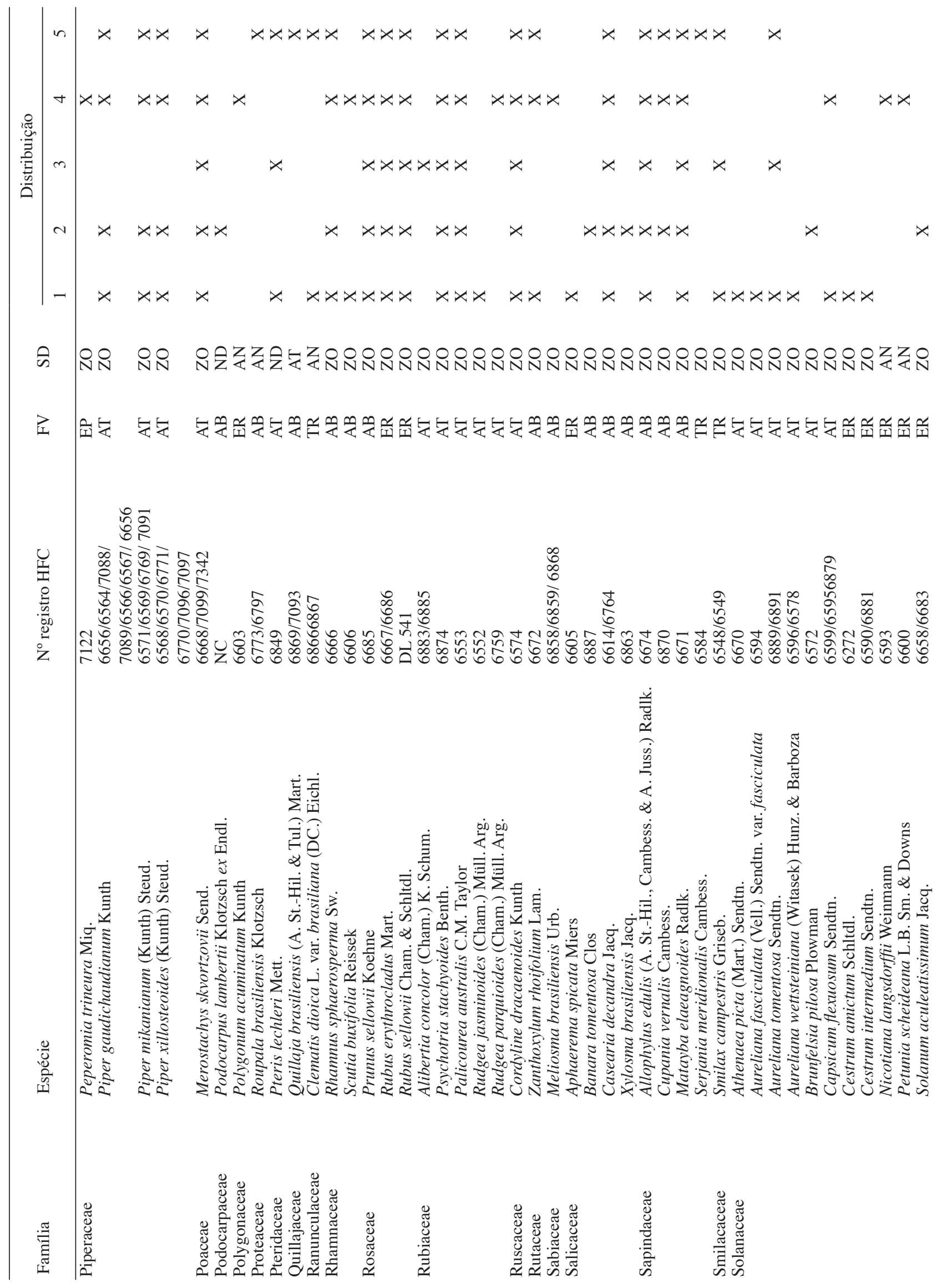




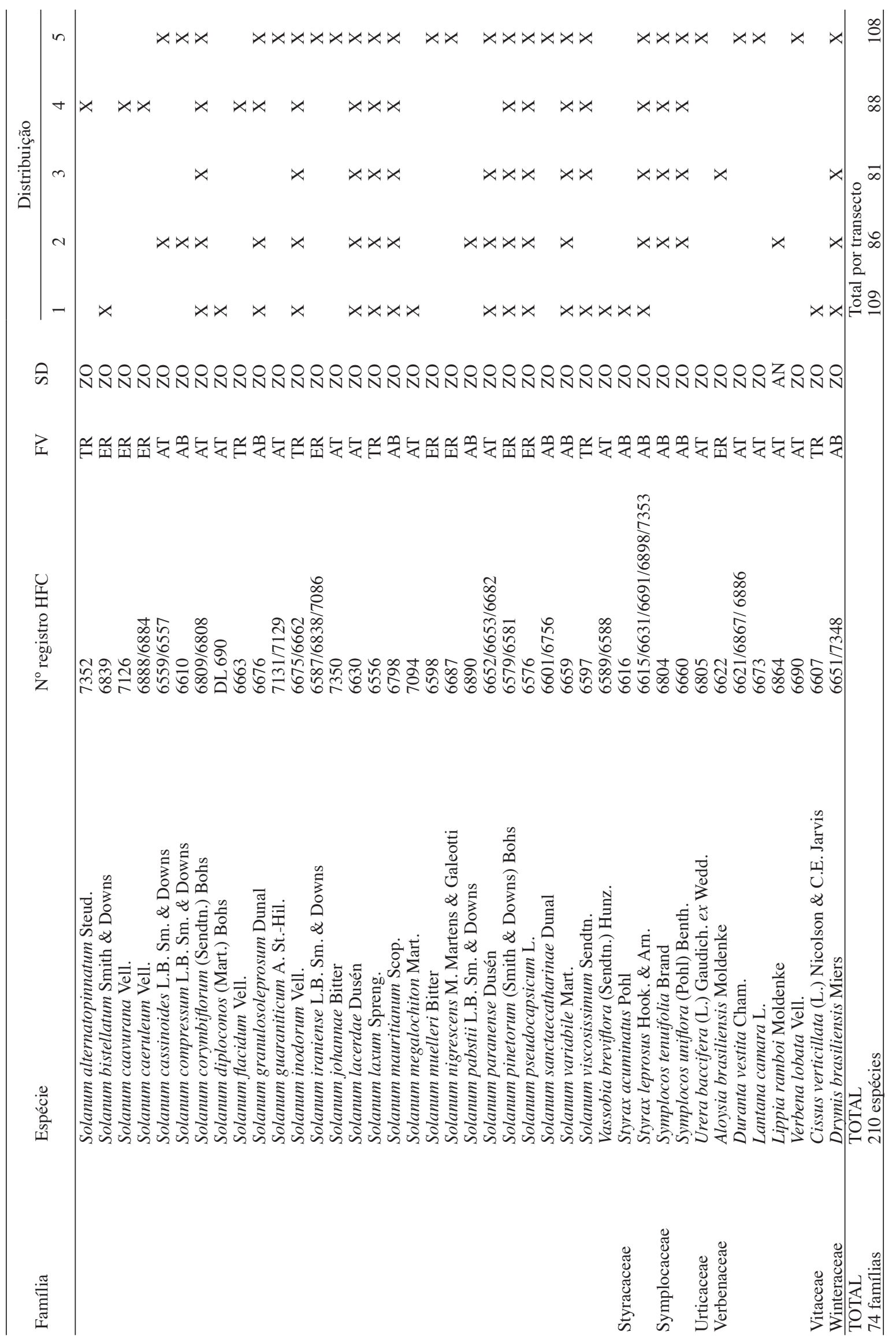




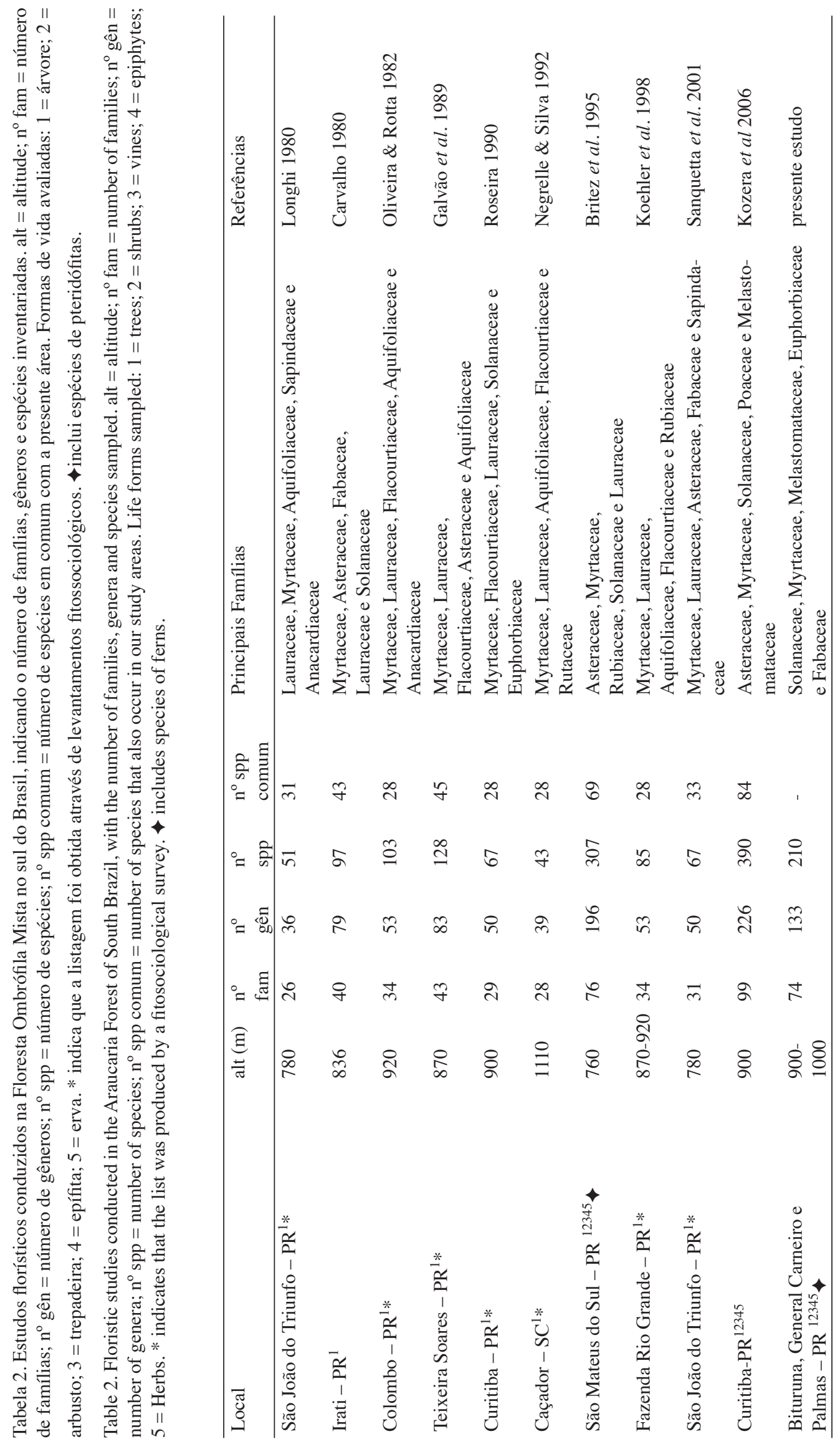


Tabela 3. Quadro comparativo da riqueza nas diferentes formas de vida entre as três áreas de FOM no PR onde foram inventariadas diversas formas de vida.

Table 3. Comparative picture of the richness in different life forms among three areas of Araucaria Forest in Parana State, Brazil, where several life forms were inventoried.

\begin{tabular}{lccc}
\hline & $\begin{array}{c}\text { Bituruna } \\
\text { (presente estudo) }\end{array}$ & $\begin{array}{c}\text { Curitiba } \\
\text { (Kozera } \text { et al. 2006) }\end{array}$ & $\begin{array}{c}\text { SMSul } \\
\text { (Britez } \text { et al. 1995) }\end{array}$ \\
\hline Árvores & 82 & 141 & 104 \\
Arbustos & 59 & 67 & 42 \\
Ervas & 37 & 129 & 104 \\
Trepadeiras & 23 & 50 & 17 \\
Epífitas & 8 & - & 34 \\
hemi-parasitas/parasitas & 2 & 3 & 2 \\
\hline
\end{tabular}

Oliveira \& Rotta 1982, Galvão et al. 1989). Porém, como os inventários florísticos geralmente são resultado de amostragens em parcelas, utilizadas em levantamentos fitossociológicos (tabela 2), o número de espécies inventariadas geralmente é inferior a 70 e limitado apenas ao estrato arbóreo (Longhi 1980, Roseira 1990, Negrelle \& Silva 1992, Sanquetta et al. 2001). Dois trabalhos (Galvão et al. 1989, Koehler et al. 1998), encontraram altos valores de riqueza (128 e 85, respectivamente). Nesses trabalhos é observado um grande esforço de campo, já que o trabalho de Galvão et al. (1989), conduzido na Flona de Irati, Município de Teixeira Soares-PR, compreendeu $18.000 \mathrm{~m}^{2}$ de parcelas e o de Koehler et al. (1998), $40.000 \mathrm{~m}^{2}$. Esses valores demonstram que o esforço de coleta pode estar diretamente relacionado ao número de espécies.

No presente estudo, as famílias mais ricas foram Solanaceae, com 39 espécies, Myrtaceae, com 15, e Melastomataceae, com 11. O gênero Solanum merece destaque, pois apresentou 28 espécies. Dentre as espécies arbóreas, destacam-se as famílias Myrtaceae, com 15 espécies, Solanaceae, com seis, e Asteraceae, com cinco espécies. De fato, a família Myrtaceae vem sendo citada por vários autores como uma das famílias mais ricas na FOM (Negrelle \& Silva 1992, Dias et al. 1998, Koehler et al. 1998, Insernhagen 2001). A alta riqueza de Solanaceae e Asteraceae pode ser explicada pelo estádio sucessional das áreas (Castella \& Britez 2004, Liebsch \& Acra 2004), pois a maioria encontra-se em estádio inicial de sucessão.

Dentre os arbustos destaca-se a família Solanaceae, com 27 espécies, seguida por Melastomataceae, com 10, e Verbenaceae, com seis. Segundo Liebsch \& Acra
(2004), as famílias Solanaceae e Melastomataceae parecem ser as famílias arbustivas mais importantes em termos de riqueza na FOM.

As espécies herbáceas foram representadas por 37 espécies. Esse número é baixo, quando comparado com outras áreas (tabela 3). Vale a pena destacar que algumas famílias que comumente são bem representadas (e.g. Poaceae, Asteraceae, etc), não foram incluídas no presente estudo.

As famílias de trepadeiras mais ricas foram Solanaceae e Passifloraceae, com cinco espécies cada, seguidas por Curcubitaceae, com quatro, e Bignoniaceae, com três. Em outras formações florestais, como a Floresta Estacional Semidecidual, o número de espécies trepadeiras geralmente ultrapassa 100 (Morellato \& Leitão Filho 1998). Fatores como clima, altitude, solo e contexto geográfico, têm sido relatados como importantes para explicar diferenças de composição para as trepadeiras (Gentry 1988). Assim, provavelmente as famílias de trepadeiras com espécies anemocóricas (p.ex. Bignoniaceae e Sapindaceae) apresentam maior riqueza em outras formações florestais porque o clima úmido e a ocorrência de geadas na FOM limitam a sua distribuição.

As espécies epifíticas apresentaram a menor riqueza, com apenas oito espécies $(3,8 \%)$, pertencentes às famílias Bromeliaceae (três espécies), Cactaceae (duas), e Gesneriaceae, Orchidaceae e Piperaceae (uma espécie cada). Embora o número de espécies epífitas (angiospérmicas) da FOM seja menor, quando comparado com Floresta Ombrófila Densa (Klein 1980 Kersten \& Silva 2002), a baixa riqueza observada na região de estudo, deve estar relacionada às grandes extensões de florestas em estádio sucessional inicial, 
onde a falta de indivíduos arbóreos com copas altas e frondosas limita a ocorrência de epífitas (Gonçalves $\&$ Waechter 2002).

As espécies parasitas foram representadas por duas espécies (1\%). A espécie Langsdorffia hypogaea é classificada como parasita obrigatória, pois os indivíduos, aclorofilados, vivem em raízes de árvores (Souza \& Lorenzi 2005). A ocorrência desta espécie em levantamentos é muito rara, pois os indivíduos são visíveis apenas no período reprodutivo. Já Struthanthus uraguensis é classificada como hemiparasita, pois tem capacidade de realizar fotossíntese e vive sobre a copa das árvores hospedeiras (Arruda \& Carvalho 2004). A distribuição dessa espécie parece ser bastante restrita, pois outros levantamentos com epífitas já na região da FOM não citam essa espécie (Kersten \& Silva 2002, Borgo \& Silva 2003). O gênero Struthanthus tem ampla distribuição nas regiões tropicais e as espécies desse gênero apresentam preferência por árvores com cascas fissuradas ou fendidas (Arruda \& Carvalho 2004). Como já salientado, a grande maioria das áreas de estudo se encontra em estádio sucessional inicial, diminuindo drasticamente potenciais hospedeiros.

Assim, as diferenças do presente estudo para aqueles conduzidos anteriormente na FOM não dizem respeito apenas ao número de formas de vida, espécies, gêneros e famílias registradas, mas também à riqueza de algumas famílias. Enquanto na maioria das áreas previamente estudadas (tabela 1) as famílias mais importantes eram Myrtaceae, Lauraceae, Asteraceae, Aquifoliaceae, Flacourtiaceae, Sapindaceae e Anacardiaceae, no presente estudo as famílias mais ricas, em ordem decrescente, foram Solanaceae, Myrtaceae e Melastomataceae. Solanaceae, com 39 espécies registradas, havia sido anteriormente reportada entre as famílias mais ricas da FOM na cidade de Curitiba (Roseira 1990), em São Mateus do Sul (Britez et al. 1995) e em Irati (Galvão et al. 1989). Myrtaceae ( $\mathrm{n}=15)$, como dito anteriormente, é freqüientemente citada como uma das famílias mais ricas dessa formação florestal (Negrelle \& Silva 1992, Dias et al. 1998, Koehler et al. 1998, Insernhagen 2001), enquanto Melastomataceae $(n=11)$ não havia sido previamente reportada entre as famílias mais ricas em espécies da FOM.

É interessante notar que mesmo o trabalho de Britez et al. (1995), que considerou todas as formas de vida (enquanto que nossas áreas as ervas foram incluídas parcialmente), encontrou resultados diferentes dos nossos, com as famílias Asteraceae, Myrtaceae, Rubiaceae, Solanaceae e Lauraceae como as mais ricas. Isso pode ser reflexo da maior riqueza dos remanescentes florestais estudados por eles. Porém, cabe salientar que na área estudada por Britez et al. (1995), a família Asteraceae, com 43 espécies, incluiu arbustos e ervas, enquanto no presente trabalho apenas as árvores dessa família foram consideradas. A família Rubiaceae é muito relacionada a ambientes de sub-bosque (Carvalho et al. 2000, Liebsch \& Acra 2004) e, portanto, a baixa riqueza dessa família na nossa área pode ser resultado do desaparecimento de espécies em função do predomínio de taquaras no sub-bosque. O elevado número de solanáceas na nossa área também deve ser reflexo do seu elevado grau de alteração, uma vez que essa família é caracterizada por espécies pioneiras, comuns em áreas alteradas (Liebsch \& Acra 2004).

Desta forma, era esperada maior riqueza para a área de estudo, considerando o potencial de algumas famílias (p. ex., Rubiaceae, Lauraceae, Fabaceae etc.). De fato, em um trecho de aproximadamente 1 km do transecto da Araucária, sob um plantio de $A$. angustifolia com cerca de 10 ha, mas sem taquaras no sub-bosque, foram registradas 90 espécies, o que representa $82,6 \%$ de todas as espécies encontradas nesse transecto e $42,9 \%$ das espécies encontradas nos cinco transectos distribuídos por três fazendas. Portanto, é o grau de alteração da maior parte das áreas amostradas que imprimiu um resultado pouco expressivo em termos de diversidade florística. Similaridade entre os transectos - Em relação à composição florística total (todas as formas de vida), os transectos se mostraram relativamente similares, variando entre $35 \%$ e $50 \%$ de espécies em comum (figura 2). O transecto que apresentou menor similaridade em relação aos demais foi o transecto do Palmital. Essa área é utilizada para criação de gado, o que acaba eliminando indivíduos regenerantes $\mathrm{e}$ indivíduos de sub-bosque, conforme já apontado por Castella \& Britez (2004). O segundo transecto com menor similaridade florística em relação aos demais foi o transecto da Araucária, já que este possui a maior riqueza florística da área de estudo. Conforme comentado acima, além de contemplar uma área de floresta secundária em estádio inicial e plantios de pinus, este transecto abriga um plantio de araucária, hoje com 40 anos de idade, sem a presença de taquaras no sub-bosque, de tal forma que ele é rico em espécies, muitas das quais não encontradas em áreas ocupadas pela taquara. Formando um agrupamento central estão os transectos da Santa Cruz, Reserva e Parque. Esses três transectos têm em comum o histórico de uso, pois 


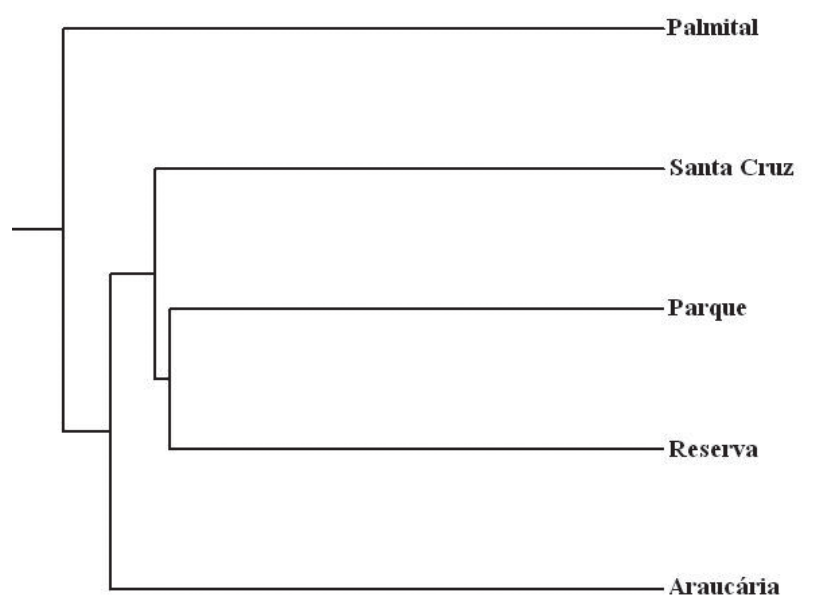

50,

100

Figura 2. Dendrograma do Índice de Similaridade de Jaccard (UPGMA) para os cinco transectos amostrados na Floresta Ombrófila Mista do centro-sul do Estado do Paraná.

Figure 2. Dendrogram of the Similarity Index of Jaccard (UPGMA) for the five transects sampled in the Araucaria Forest of mid-southern Parana state, Brazil.

sofreram corte seletivo de essências florestais nativas na metade do século XX e foram, posteriormente, abandonados. Assim, esses três transectos formam uma fitofisionomia, aparentemente, dominante não só nas áreas da Remasa Reflorestadora, mas também na região centro-sul do estado do Paraná, onde a maioria dos remanescentes de Floresta com Araucária foi explorada no passado e apresenta subbosque dominado por taquaras, apontadas como o principal fator biótico que impede a regeneração de espécies arbóreas (Smith et al. 1981, Castella \& Britez 2004).

Síndromes de dispersão - Nas 210 espécies encontradas nas áreas de estudo, a síndrome melhor representada foi a zoocoria, com 144 espécies $(68,6 \%)$, seguida pela anemocoria, com $46(21,9 \%)$, e a autocoria, com $14(6,7 \%)$, lembrando que seis espécies $(2,9 \%)$ não foram classificadas quanto à síndrome de dispersão dos diásporos. Ao analisar as síndromes para cada forma de vida, separadamente, os resultados repetemse para árvores e arbustos. Assim, entre as árvores, a zoocoria esteve representada por 61 espécies $(78,2 \%)$, seguida pela anemocoria, com $10(12,8 \%)$, e a autocoria, com apenas sete $(6,9 \%)$ (figura 3 ). Dentre as espécies arbustivas, a zoocoria também foi mais freqüiente, abrangendo 42 espécies $(72,4 \%)$, seguida pela anemocoria, com 26 (26,5\%), e pela autocoria, com sete $(7,1 \%)$. Nas espécies herbáceas, a zoocoria foi a mais freqüente com 19 espécies $(52,8 \%)$, seguida por anemocoria com $16(44,4 \%)$ e autocoria com apenas 1 espécie $(2,8 \%)$. Entre as trepadeiras e as epífitas, a maior freqüência foi da anemocoria, com seis $(26,1 \%)$ e cinco espécies $(62,5 \%)$, respectivamente (figura 3). As espécies trepadeiras com dispersão zoocórica foram seis $(26,1 \%)$, enquanto que nas epífitas esta síndrome estava presente em apenas três $(37,5 \%)$ espécies. A autocoria não foi observada nas espécies trepadeiras e epifíticas. As espécies parasitas não foram incluídas na figura 3 , pois em apenas uma espécie pode ser determinada a sua síndrome (zoocórica); a outra permaneceu sem classificação.

Essa maior proporção de espécies arbóreas zoocóricas é esperada para florestas úmidas brasileiras (Tabarelli et al. 1999, Tabarelli \& Peres 2002), bem como para a FOM (Rondon Neto et al. 2001). A dispersão anemocórica poder ser considerada uma adaptação das espécies para ocupar ambientes abertos, onde o vento é mais freqüente e intenso em comparação com o interior das florestas (Tabarelli et al. 1999, Hill \& Curran 2003). De fato, a anemocoria foi a síndrome mais comum entre as espécies trepadeiras e epífitas já que segundo, Oliveira \& Moreira (1992), o vento favorece a dispersão de frutos e sementes em alturas elevadas.

As espécies autocóricas representaram um pequeno porcentual das espécies amostradas nas áreas de estudo. Essa baixa proporção de espécies autocóricas, no entanto, é comum em diversas formações florestais (Tabarelli et al. 1999, Rondon Neto et al. 2001). Além disso, as espécies autocóricas são representadas, principalmente, pela família Euphorbiaceae.

Os resultados obtidos permitem considerar que, embora tenha sido registrado um número relativamente elevado de espécies $(n=210)$ nos remanescentes de Floresta Ombrófila Mista estudados na região centrosul do Paraná, a riqueza total e de espécies arbóreas foi inferior àquela encontrada em outras áreas previamente estudadas na mesma formação florestal. Aliada a baixa riqueza, o histórico de perturbação (extração seletiva) das nossas áreas, fornece indícios que houve um empobrecimento florístico, conforme previsto por Veríssimo et al. (1995), Laurence (1999) 


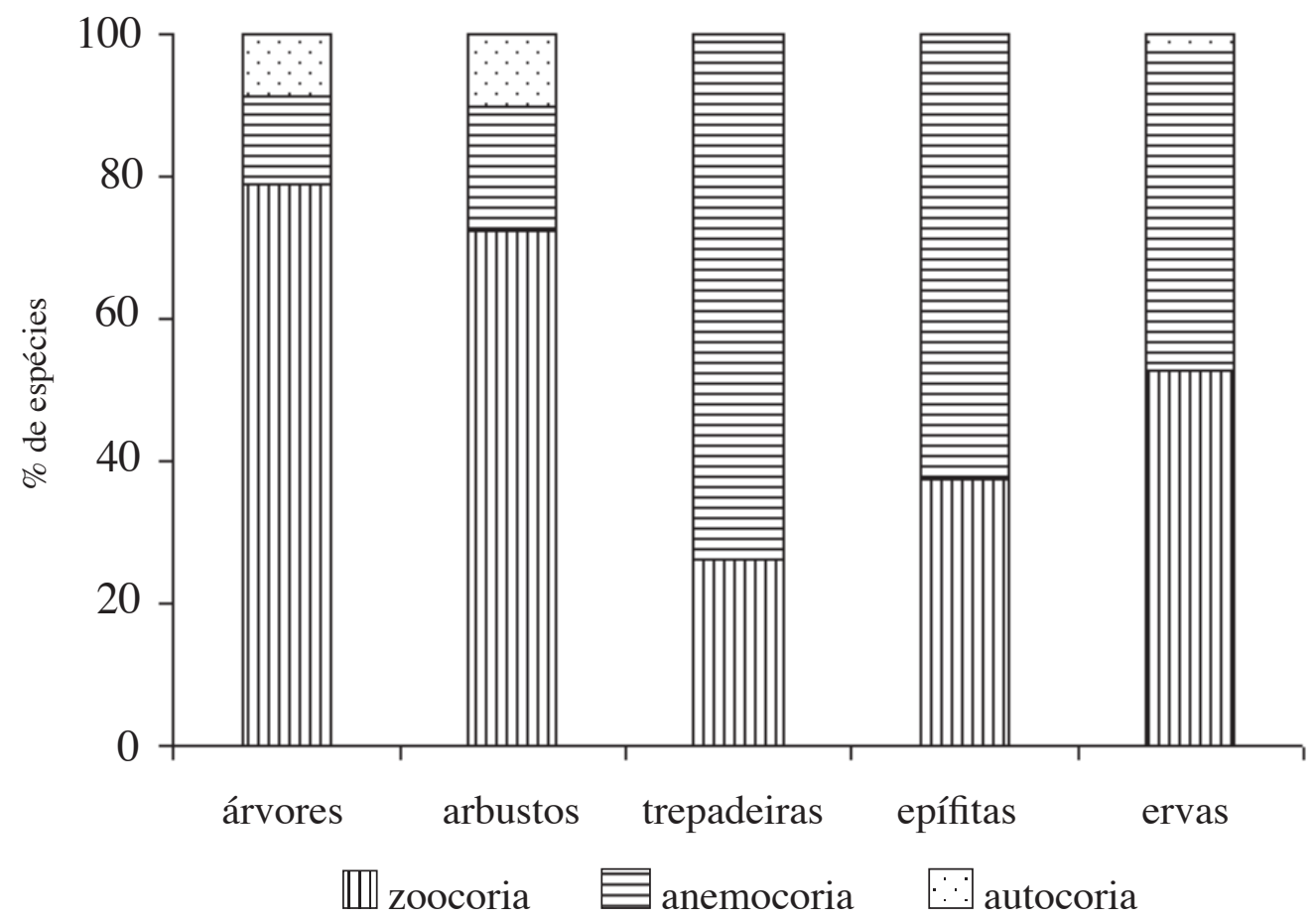

Figura 3. Síndromes de dispersão (em porcentagem) em quatro formas de vida encontradas em fragmentos de Floresta Ombrófila Mista na região centro-sul do Estado do Paraná.

Figure 3. Dispersal syndromes (in percentage) of four different live forms of plant species found in fragments of Araucaria Forest in the mid-southern Parana state, Brazil.

e Tabarelli \& Gascon (2005). O fato de grandes extensões territoriais da FOM na região centro-sul do estado do Paraná estarem ocupadas por vegetação em estádio inicial e médio de regeneração, tal como o observado nos remanescentes florestais estudados, é preocupante, pois nessas áreas há descontrole populacional de taquaras (Smith et al. 1981, Liebsch \& Reginato, dados não publicados), o que parece comprometer a regeneração das demais espécies.

\section{Agradecimentos}

O presente trabalho fez parte do projeto "Avaliação da população e dos hábitos alimentares do macacoprego (Cebus apella, Cebidae, Mammalia) e seu impacto em plantações comerciais de Pinus spp. e Araucaria angustifolia, para subsidiar propostas de manejo" uma parceria entre Embrapa Florestas e Remasa Reflorestadora Ltda. Os autores agradecem a Aline Dal'Maso pelo auxílio no trabalho de campo; a Gerdt Hatschbach, Marcos Sobral e Lilian Auler Mentz pela determinação de parte do material botânico.

\section{Literatura citada}

APG II. 2003. An update of the Angiosperm Phylogeny Group classification for the orders and families of flowering plants: Angiosperm Phylogeny Group II. Botanical Journal of the Linnean Society 141: 399436.

Arruda, R. \& Carvalho, L.N. 2004. Especificidade de hospedeiros por Struthanthus polyanthus (Loranthaceae) em uma área de Cerrado do Parque da Serra de Caldas Novas, GO, Brasil. Bioscience Journal 20: 31-36.

Borgo, M. \& Silva, S.M. 2003. Epífitos vasculares em fragmentos de Floresta Ombrófila Mista, Curitiba, Paraná, Brasil. Revista Brasileira de Botânica 26: 391-401.

Britez, R.M., Silva, S.M., Souza, W.S. \& Motta, J.T.W. 1995. Levantamento florístico em Floresta Ombrófila Mista. São Mateus do Sul, Paraná, Brasil. Arquivos de Biologia e Tecnologia 38: 1147-1161.

Carvalho,P.E.R. 1980. Levantamento florístico da Região de Irati-PR ( $1^{\text {a }}$ aproximação). Circular Técnica da Embrapa Florestas (Colombo) 3. 
Carvalho, L.M.T., Fontes, M.A.L. \& Oliveira Filho, A.T.2000. Tree species distribution in canopy gaps and mature Forest in an area of cloud Forest of the Ibitipoca Range, south-eastern Brazil. Plant Ecology 149: 9-22.

Castella, P.R. \& Britez, R.M. 2004. A Floresta com Araucária no Paraná: conservação e diagnóstico dos remanescentes florestais. Ministério do Meio Ambiente, Brasília.

Dias, M.C., Vieira, A.O.S., Nakajima, J.N., Pimenta, J.A. \& Lobo, P.C. 1998. Composição florística e fitossociologia do componente arbóreo das florestas ciliares do rio Iapó, na bacia do rio Tibagi, Tibagi, PR. Revista Brasileira de Botânica 21: 183-195.

Galvão, F., Kuniyoshi, Y.S. \& Roderjan, C.V. 1989. Levantamento fitossociológico das principais associações arbóreas da Floresta Nacional de Irati-PR. Floresta 19: 30-49.

Gentry, A.H. 1988. Changes in plant community diversity and floristic composition on environmental and geographical gradients. Annals of the Missouri Botanical Garden 75: 1-34.

Gonçalves, C. \& Waechter, J.L. 2002 . Epífitos vasculares sobre espécimes de Ficus organensis isolados no norte da Planície Costeira do Rio Grande Do Sul: padrões de abundância e distribuição. Acta Botanica Brasilica 16: 429-441.

Hill, J.L. \& Curran, P.J. 2003. Area, shape and isolation of tropical forest fragments: effects on tree species diversity and implications for conservation. Journal of Biogeography 30: 1391-1403.

Lao S.L. 1999. Light gaps disturbance, recruitment limitations and tree diversity in a neotropical forest. Science 283: 554-557.

IBGE. 1992. Manual técnico da vegetação brasileira. Instituto Brasileiro de Geografia e Estatística, Rio de Janeiro.

Insernhagen, I. 2001 . A fitossociologia florestal no estado do Paraná e os programas de recuperação de áreas degradadas: uma avaliação. Dissertação de Mestrado, Universidade Federal do Paraná, Curitiba.

Kersten, R.A. \& Silva, S.M. 2002. Florística e estrutura do componente epifítico vascular em floresta ombrófila mista aluvial do rio Barigüi, Paraná, Brasil. Revista Brasileira de Botanica 25: 259-267.

Klein, R.M. 1980. Ecologia da flora e vegetação do Vale do Itajaí. Sellowia 31: 1-389.

Klein, R.M. 1960. O aspecto dinâmico do pinheiro brasileiro. Sellowia 12: 17-44.

Koehler, A., Péllico Netto, S. \& Sanqueta, C.R. 1998. Análise da estrutura de uma Floresta Ombrófila Mista semidevastada, Fazenda Gralha Azul, Região Metropolitana de Curitiba, com implicações ao manejo. Revista Acadêmica 1: 37-60.

Kozera, C., Dittrich, V.A.O. \& Silva, S.M. 2006. Composição florística da Floresta Ombrófila Mista
Montana do Parque Municipal do Barigüi, Curitiba, PR. Floresta 36: 45-58.

Laurance, W.F. 1999. Refections on the tropical deforestation crisis. Biological Conservation 91: 109117.

Liebsch, D. \& Acra, L.A. 2004. Riqueza de espécies de sub-bosque de um fragmento de floresta ombrófila mista em Tijucas do Sul, PR. Ciência Florestal 4: 67-76.

Longhi, S. J. 1980. A estrutura de uma floresta natural de Araucaria angustifolia (Bert.) O. Ktze, no sul do Brasil. Dissertação de Mestrado, Universidade Federal do Paraná, Curitiba.

Maack, R. 1981. Geografia física do Estado do Paraná. José Olympio, Curitiba.

Missouri Botanical Garden. http://www.tropicos.org (acesso em 20.01.2008).

MMA 2000. Avaliação e ações prioritárias para a conservação da biodiversidade da Mata Atlântica e Campos Sulinos. Ministério do Meio Ambiente, Brasília.

Morellato,L.P.C.\& Leitão Filho,H.F. 1998. Levantamento florístico da comunidade de trepadeiras de uma floresta semidecídua no Sudeste do Brasil. Boletim do Museu Nacional, Botânica 103: 1-15.

Negrelle, R.A.B. \& Silva, F.C. 1992. Fitossociologia de um trecho de floresta com Araucaria angustifolia (Bert.) O. Ktze. no município de Caçador - SC. Boletim de Pesquisa Florestal 24/25: 37-54.

Oliveira, Y.M.M. \& Rotta, E. 1982. Levantamento da estrutura horizontal de uma mata de Araucária do primeiro planalto paranaense. Boletim de Pesquisas Florestais 4: 1-46.

Oliveira, P.E.A.M. \& Moreira, A.G. 1992. Anemocoria em espécies do cerrado e mata de galeria de Brasília, DF. Revista Brasileira de Botânica 15: 163-174.

Oliveira Filho, A.T., Vilela, E.A., Galvilanes, M.L. \& Carvalho, D.A. 1994. Effect of flooding regime and understorey bamboos on the physiognomy and tree species composition of a tropical semideciduous forest in southeastern Brazil. Vegetatio 113: 99-124.

Pijl, L. van der. 1972. Principles of dispersal in higher plants. 2 ed. Springer-Verlag, Berlin.

Roderjan, C.V., Galvão, F., Kuniyoshi, Y.S. \& Hastschbach, G.G. 2002. As unidades fitogeográficas do estado do Paraná. Ciência \& Ambiente 24: 75-92.

Roseira, D.S. 1990. Composição florística fitossociológica do bosque com Araucaria angustifolia (Bert.) O. Kuntze no parque Estadual João Paulo II, Curitiba, Paraná. Dissertação de Mestrado, Universidade Federal do Paraná, Curitiba.

Rondon Neto, R.M., Watzlawick, L.F. \& Caldeira, M.V.W. 2001. Diversidade e síndromes de dispersão de diásporos das espécies arbóreas de um fragmento 
de Floresta Ombrófila Mista. Revista Ciências Exatas e Naturais 3: 209-216.

Sanquetta, C.R., Pizzatto, W., Péllico-Netto, S., Eisfeld, R.L. \& Figueiredo Filho, A. 2001. Estrutura vertical de um fragmento de Floresta Ombrófila Mista no centrosul do Paraná. Revista Ciências Exatas e Naturais 3: 59-73.

Silva, A.F. \& Shepherd, G.J. 1986. Comparações florísticas entre algumas matas brasileiras utilizando analise de agrupamento. Revista Brasileira de Botanica 9: 81-86.

Smith, L.B., Wasshausen, D.C. \& Klein, R.M. 1981 Gramíneas.In: R. Reitz (ed.). Flora Ilustrada Catarinense. Herbário Barbosa Rodrigues, Itajaí.

Souza, V.C. \& Lorenzi, H. 2005. Botânica Sistemática: Guia ilustrado para a identificação das famílias de Angiospermas da flora brasileira, baseado em APG II. Instituto Plantarum, Nova Odessa.
Tabarelli, M. \& Gascon, C. 2005. Lições da pesquisa sobre fragmentação: aperfeiçoando políticas e diretrizes de manejo para a conservação da biodiversidade. Megadiversidade 1: 181-188.

Tabarelli, M. \& Peres, C.A. 2002. Abiotic and vertebrate seed dispersal in the Brazilian Atlantic forest: implications for forest regeneration. Biological Conservation 106: 165-176.

Tabarelli,M., Mantovani, W. \& Peres, C.A. 1999. Effects of habitat fragmentation on plant guild structure in the montane Atlantic forest of southeastern Brazil. Biological Conservation 91: 119-127.

Veríssimo, A., Barreto, P., Tarifa, R. \& Uhl, C. 1995. Extraction of a high-value natural resource in Amazonia: the case of mahogany. Forest Ecology and Management 72: $39-60$

Vidal,W.N.\& Vidal,M.R.R. 1984. Botânica-Organografia. Imprensa da Universidade Federal de Viçosa, Viçosa. 